\title{
Acquisitive Desire in Early Childhood: Rethinking Rivalry in the Playroom
}

\author{
Deseo de apropiación en la infancia: repensar \\ la rivalidad en la sala de juegos
}

\begin{abstract}
What if we could observe the normal operation of mimetic desire in a rivalry-free environment? What would object relationships look like? Would acquisitive desire make an appearance without the encouragement of the model-obstacle dynamic? Montessori's teacher training method offers a rigorous approach to removing rivalry from the student-teacher relationship. It is designed and functions to prevent the modelobstacle phenomenon from occurring. Therefore it provides us with a laboratory for observing mimetic desire in as close to a pre-lapsarian state as we can approximate this side of the gates of Eden.
\end{abstract}

KEY WORDS: Montessori, education, mimesis, Girard, model, rivalry.

\begin{abstract}
¿Y si pudiéramos observar el funcionamiento normal del deseo mimético en un ambiente libre de rivalidad? ¿Cómo serían las relaciones de los objetos? ¿Habría aparecido el deseo adquisitivo sin el estímulo de la dinámica modelo-objeto? El método de formación de profesores de Montessori ofrece un riguroso enfoque para eliminar la rivalidad de la relación estudiante-profesor. Está diseñado y funciona para prevenir que el fenómeno del modelo-obstáculo tenga lugar. Por lo tanto, nos proporciona un laboratorio para observar el deseo mimético lo más cerca posible a un estado pre-lapsario de este lado de las puertas del Edén.
\end{abstract}

PALABRAS CLAVE: Montessori, educación, mímesis, Girard, modelo rivalidad.

What if we could observe the normal operation of mimetic desire in a rivalry-free environment? What would object relationships look like? Would acquisitive desire make an appearance without the encouragement of the model-obstacle dynamic? Montessori's teacher training method offers a rigorous approach to removing rivalry from the student-teacher relationship. It is designed and functions to prevent the model-obstacle phenomenon from occurring. Therefore it provides us with a laboratory for observing mimetic desire in as close to a pre-lapsarian state as we can approximate this side of the gates of Eden.

Since the 1960s René Girard, accompanied by an ever-expanding cadre of researchers, has produced breakthroughs in the social sciences by doing the unfashionable: taking the role 
of imitation in human behavior seriously. Sixty years earlier, Dr. Maria Montessori launched a revolution in children's education by doing the same thing. Despite this similarity, their work yields striking contrasts. While Girard's theory reveals the pivotal role of acquisitive desire in conflict and violence, Montessori's educational method reveals the peaceful acquisitiveness of childhood desire.

Mimetic theory distinguishes the human species from other animals in terms of our excessive mimeticism. Whether acquisitive desire served a purpose in the evolution of our species is beyond the purview of this paper. What I propose to examine is the role of acquisitive desire in the journey from birth to adulthood. By examining childhood desire, I believe we can shed light on the non-conflictual role of acquisitive desire, an area awaiting further research by mimetic theorists.

Montessori has a contribution to make to this discussion because she insisted that she did not develop a method of education so much as «discover the child». What the child revealed to her was that human beings are not naturally conflictual despite their mimeticism. «Normalized» children, as she called them, children liberated from adult rivalry, were instinctively acquisitive and remarkably peaceful. Like Girard, she described the process by which children are liberated from the influence of rivalry as a conversion.

I will propose that Montessori's revolution in education presents us with a laboratory in which to observe the regular operation of acquisitive desire without rivalry. A close look at Montessori's method will reveal 1) the developmental role of acquisitive desire before it reaches the stage of conflict, 2) the routine and yet mimetically driven phenomenon of peaceful object disappearance, and 3) the intrinsic value of disappearing objects. Just as mimetic mechanisms generated a false sacred obscuring the true appearance of God in our midst, so mimetically generated value has obscured the intrinsic value of the created world and the peaceful functioning of acquisitive desire.

\section{The Playroom}

Because most of us have witnessed children engaged in what appears to be irrational conflicts over objects of little value, the child's playroom has been used by Girard and adopted by popularizers of his mimetic theory to dramatize the connection between mimetic desire and conflict. Here's how the playroom example works to illustrate this phenomenon:

Imagine a small child in a room full of toys. He is only casually engaged with a toy nearby. Another child enters the room and surveys the toys. Which one will she choose? It will most likely be the toy the first child seems interested in, because even that casual interest makes that toy more desirable than all the others. As she reaches for the toy, the first child's interest is suddenly enflamed. He may shout, «l had it first!» and tussle with her for possession of an object he hardly desired until she seemed to want it. They may come to blows over something neither of them wanted all that badly until the other one wanted it, too ${ }^{[1]}$. 
In the playroom scenario, the second child's desire is awakened by the first child's casual gesture, demonstrating the role of the mediator and the triangular nature of desire. Jean-Michel Oughourlian defines desire as psychological movement, «an energy» that «presupposes a finality, that is, a goal toward which its trajectory can be oriented "..2 We are drawn to certain models or mediators of desire «because we feel an inner attraction to them... anyone whose superior qualities we recognize and would like to have for our own".

To children, of course, all adults exist in a nearly godlike state of perfection endowed with «superior qualities» which exert a powerful attraction. As Ourghourlian explains, «In this sense, mimetic desire is always a desire "to be", to exist in greater measure, a desire for an achievement or a dreamed-of completeness that one might feel stands before one but is being held onto by the other $\gg .{ }^{[3]}$ (emphasis mine) This desire to be is called metaphysical desire, an apt name for the healthy pattern of desire which motivates children to take adults as their models.

In his explanation, Ourghourlian has also correctly introduced the element that causes metaphysical desire to become conflictual: the model must designate the goal of desire and simultaneously block access to that goal. When the model functions as an obstacle, the desire to possess the being of the model fixates on the withheld object. The secret of the model's completeness appears to reside in the forbidden object, or so the «logic» of mimetic desire has it. Girard calls this manifestation of desire acquisitive because it has become fixated on a particular object. In this way objects become imbued with the metaphysical being of their models, an excess of meaning that they do not intrinsically possess.

Girard has observed that at the stage of acquisitive desire the rivals share a delusion: each sees their desire as original and denies that the other's desire is enflaming their own. Blind to the role of imitation, the rivals see each other as obstacles to the fulfillment of what they insist is their authentic desire. Inevitably, the rivals' denial precipitates a shift in the focus of their attention from the object to one another. Each now desires nothing more than the defeat of the rival and so the object which began it all becomes increasingly irrelevant. Indeed, Girard has stated explicitly that "for the mimesis to become purely antagonistic the object has to disappear». ${ }^{[4]}$ (emphasis mine) Though the rivals continue to testify to its value, the object may become a casualty of the conflict as the rivals would rather see it destroyed than fall into the wrong hands.

Which brings us back to the question raised by the Girardian playroom: Is it a good representation of childhood desire? I have no doubt that it serves to illustrate the rivalry associated with acquisitive desire in adults, but is acquisitive desire the natural state of metaphysical desire in childhood? Don't the temper tantrums, irrational desires, defiance, fighting and rivalries we have all observed in children, provide ample evidence to answer in the affirmative?

A teacher new to the Montessori method writing to Dr. Montessori sometime after World War I offers a good example of this type of disruptive childhood behavior. Miss G., as Montessori identifies her, had set up the prepared environment for her students as she had learned in her Montessori training but her attempt seemed at first to be a dismal failure. Here's how Miss G. described it in a letter to Dr. Montessori:

The children snatched the objects from each other's hands. If I tried to show something to one of them, the others would drop what they had in their hands and gather noisily about me. When I finished explaining an object, they would all fight for it. The children showed no real interest in the various 
materials. They passed from one object to another without lingering over any of them. One child was so incapable of staying in one place that he could not remain seated long enough to run his hands over any of the objects given to him. In many instances the movement of the children was aimless: they simply ran about the room heedless of the damage done. They ran into the table, upset chairs and trampled upon the material provided for them. Sometimes they would begin to work in one spot, then run off, take another object, and then abandon it for no reason whatever. ${ }^{[5]}$

Not a pretty picture, but is it an accurate picture of normal childhood desire? Girard predicts that as rivalry spreads, communities are subject to the risk of self-destruction in a war of all against all. Unless they find a way to re-establish unity, which is often at the expense of a scapegoat. In Miss G's classroom the children flitted from one object to another as if in search of a powerful enough model to direct their attention. They were a primal horde of undifferentiated conflict in search of a unifying force and one might reasonably expect a scapegoating solution to be discovered by the children or seized upon in desperation by the unfortunate Miss $\mathrm{G}$.

Yet Dr. Montessori saw in this behavior a distortion of the child's true nature. In fact, she saw it as evidence that the purpose of this early stage in human life had been thwarted and undermined by adults blissfully unaware of their unconscious rivalry with the child's life. Childhood development depends upon the free exercise of acquisitive desire before it becomes infected with rivalry. Desire in this early manifestation is an extreme openness to the influence of the world such that the world is incarnating itself in the child. Children are "acquiring» the world in the most literal sense of the word and being made in the world's image. Rivalry poisons that process, interfering with the natural fluidity of mimetic desire, as witnessed by Miss $G$.

As we shall see, the means of acquiring being for the child is the acquisition of objects in the environment. As Montessori's insights about child development reveal, metaphysical and acquisitive desire form a natural and peaceful unity in early childhood. Acquisition of objects, as children perform it, is essential to the acquisition of being and therefore demonstrates a pattern of desire that does not result in rivalry or conflict or the problematic disappearance of the object.

\section{A Theory of Desire in Childhood}

The reason that the rightful role of objects in the acquisition of being has not been explored more fully may be that, as we see in the playroom example, mimetic theory has taken for granted an identity between childhood and adult desire. This is something that Girard himself has denied, albeit too meekly. In his zeal to persuasively present the connection between conflict and desire, he regretfully under-represented nonconflictual desire. In his introduction to Roel Kaptein's exploration of mimetic desire and peacemaking, On the Way of Freedom, René Girard said: «Imitative desire wants nothing more than to be free from imitation. Complete selfsufficiency is its ultimate idol. If it were the author's goal as well, he would move away from genuine spontaneity which is not the absence of mimetic behavior but the most naïve and innocent imitation of all, that of a little child, the attitude recommended by Jesus».[6] 
There is, of course, nothing naïve and innocent about adult desire which denies its mimetic aspects. Montessori realized, however, that children are not in denial about their reliance on their models. In fact, they are unabashed imitators, so much so that Jesus held them up as role models for adults to follow (Matthew 18). For to be a follower of Jesus, one must first of all not be ashamed to be a follower. Shame is a constant companion of adult desire, and children can easily become infected by it. For now it is enough to observe with Montessori that the «finality» of newborn desire is the development of the individual the child will become and the means of achieving that end is unabashed mimetic engagement with the objects in their environment.

Montessori called the naïve and innocent imitation of childhood the Absorbent Mind.

Only after repeated experiments did we conclude with certainty that all children are endowed with this capacity to «absorb» culture... It may be said that we [adults] acquire knowledge by using our minds; but the child absorbs knowledge directly into his psychic life. Simply by continuing to live, the child learns to speak his native tongue. A kind of mental chemistry goes on within him... Impressions do not merely enter his mind; they form it. They incarnate themselves in him. The child creates his «mental muscles», using for this what he finds in the world around him. We have named this type of mentality, The Absorbent Mind. ${ }^{[7]}$

While Girard is careful to distinguish mimetic desire from drives for food or sex or shelter, Montessori discovered that raw mimeticism is more like hunger or sexual desire than it is like the object desires of adults equipped with consciousness. In pre-conscious children, mimetic desire functions to allow the development of consciousness itself and so as such it functions more as an instinct or drive. Most adults readily agree that newborns are not miniature adults who simply must be fed and watered to grow into larger versions of themselves. Yet we often neglect to fully consider the implications of the fact that the event of being born does not end genetically guided development. This results in a failure to consider that mimetic desire has a particular function in childhood that the achievement of adulthood renders obsolete.

The child has great powers that we adults no longer possess; he is thus a creature who is different from us. We, too, have great powers, of course. We can reason logically, for instance. But the child has a power that we do not have - that of building man himself. ${ }^{[8]}$

In childhood, all objects are potentially fascinating and able to be called into service of the developing self. Children need no one to tell them that the sights, sounds, smells, tastes and textures in their environment are worthy of their attention. These inherent qualities exert a draw on the child's senses generating an instinctive attention which is necessary and beneficial. Which objects exert a draw on the child is determined by, as Montessori called it, the internal guide of the Absorbent Mind.

In the language of mimetic theory, we can say that the child's attention to objects in its ken is mediated by the Absorbent Mind. But the environment itself is mediated by adults. It can 
either be one that is rich with materials that provide suitable experiences for the child's developmental needs. Or it can be one strictly attuned to adult needs, serving adult desires for comfort, entertainment, and convenience. A proper Montessori classroom is an environment prepared with activities to allow for the «free activity» required by the Absorbent Mind.

Whenever Montessori uses the term «free» she is always referring to «freedom from adult interference». In mimetic theory terms, we would say freedom from mimetic rivalry. ${ }^{\left[{ }^{[9]}\right.}$ Dr. Montessori observed that an embedded and ubiquitous rivalry exists between children and adults, one in which the child consistently finds himself on the losing end. Dr. Montessori said that the child

.... is the Forgotten Citizen, who lives in a world where there is plenty of everything for everyone else, but nothing for him. In this empty world he wanders aimlessly, getting constantly into mischief, breaking his toys, vainly seeking satisfaction for his spirit, while the adult fails completely to realize what are his real needs. ${ }^{[10]}$

To remedy the givenness of rivalry in the child's environment, the entire Montessori classroom is structured to conform to the child's modus operandi, which is to learn not as adults learn through logic or argument or spoken word but through the senses. The classroom is populated with child size furniture and manipulative materials appealing to sight, hearing, tactile exploration, even taste. The activities cover fine and gross motor activities, skills for everyday life such as pouring and food preparation, and academic areas such as reading and writing, math, geography, botany, and zoology. Within this nonrivalrous environment, children are allowed the freedom to choose the activity that interests them and to work with it for as long as they like. While they are guided by the teacher and introduced to new materials by way of demonstrations, very little intervention on the part of the teacher is supposed to take place.

So much freedom for the child and so little intervention by the teacher continues to be viewed with skepticism as a recipe for chaos and confusion. Yet when Montessori observed children who were free to follow the direction of their inner guide, the Absorbent Mind, she found that they were remarkably peaceful and calm. At the moment that Montessori was able to match a learning material to a developmental need, an intense focus appeared in the child. Children as young as two exhibited an extraordinary capacity for prolonged periods of concentration, a love of order, a drive to help with all areas of adult life, including washing dishes, sweeping the floor, and doing the laundry. Montessori realized that what the children longed for was child-sized materials presented to them slowly and discretely so each step could be observed and absorbed by their eager minds. They would then engage with the activity over and over again, perfecting their skills to their satisfaction. At which point they moved naturally to another object or activity of interest.

Let's return to the chaotic scene in Miss G.'s classroom, to see what effect the prepared environment can have on children infected with rivalry. Miss $\mathrm{G}$. describes what happened to the children:

In a few days that nebulous mass of whirling particles (the disorderly children) began to take on a definite shape. It seems as if the children began to give themselves direction. They started to take interest in objects which 
they had originally despised as silly toys. As a result of this new interest they began to act as independent beings. An object which absorbed the complete attention of a child would not have the least attraction for another; the children pursued their own separate interests.

The battle is finally won when a child finds something, some particular object, that spontaneously arouses his intense interest... As soon as children find something that interests them they lose their instability and learn to

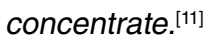

As we can see here, the aim of the child's interaction is not possession of the object. In fact, objects lose their fascination when their purpose is exhausted. "Intense interest» lasts only as long as interacting with it serves that child's developmental needs. In other words, interest wanes once the shape, feel, heft and function of the object has been «absorbed» into the muscular and psychic memory via the child's physical manipulation of it. As Miss G. observed, one child's «normalized» desire, what we can call a spontaneous interest in an object or activity, was not contagious to the others -each child was driven by different needs to objects required for their growth. Their Absorbent Minds imbued different objects with value.

\section{Acquisitive Desire in the Child}

The necessity of interaction between child and environment, which includes human beings and all elements of culture, is not in question in child development today. Even in medical discussions of embryonic development, environmental factors are counted as an influence. The same is said of brain development outside the womb. In his introduction to Descartes'Error: Emotion, Reason and the Human Brain, Antonio Damasio explains the current understanding of brain development:

The physiological operations that we call mind are derived from the structural and functional ensemble rather than from the brain alone: mental phenomena can be fully understood only in the context of an organism's interacting in an environment. That the environment is, in part, a product of the organism's activity itself, merely underscores the complexity of interactions we must take into account. ${ }^{[12]}$

Dr. Montessori makes the same conclusion regarding the interplay between genetically guided development and the environment. Here she comments on the young child's seeming obsessive interest in repeating mundane, apparently aimless, behaviors such as carrying large objects from one place to another and back again:

[The repetition] proves that the external aim was only a stimulus. The real aim was to satisfy an unconscious need, and this is why the operation is formative, for the child's repetition was laying down in his nervous system an entirely new system of controls, in other words, establishing fresh co-ordinations between his muscles, co-ordinations not given by nature, but having to be acquired. ${ }^{[13]}$ 
The musculature of the child's body does not develop without use. Working with objects and moving through the environment is essential for the healthy development of hands, arms, legs, neck and body. Birth, it seems, is simply the event by which the sphere of opportunity for the interactions required by the developing organism is enlarged. Interestingly for our discussion, Montessori observed that the child's initial efforts at acquiring the ability to move, to direct his own muscles in a coordinated way toward a goal, is that of grasping. She writes:

The first sign of movement is the child's effort to grasp or take something. Not till grasping has occurred is the baby's attention drawn to the hand which enabled him to do it... Intentional grasping, impelled by his wishes, then ceases to be grasping pure and simple. It gives way to true exercises of the hand expressed particularly in the moving of objects here and there. Possessor of a clear vision of his surroundings, and full of desires in regard to them, the child begins to act. ${ }^{[14]}$

Unintentional grasping directed by an inner drive, leads to awareness of one's hand and the awakening of conscious intention. The aim of grasping in the child is not to possess an object in the adult sense of «possession». By virtue of being used the object becomes an agent of change acting upon the child. This is an intensely reciprocal relationship, tightly binding the developing body of the child to physical engagement with the world. Like the lightning fast exchange of desires such that model and subject «influence and imitate each other simultaneously, so that ultimately no one can know who is copying whom,${ }^{[15]}$ the child and object are in a dance of mutual influence.

Harmonious interaction -when it exists, as in the child- represents the normal relationship that should exist between the individual and his surroundings. And this relationship is one of love. Love impels the child not toward the possession of an object, but toward the work he can do with it. ${ }^{[16]}$

In childhood, then, possession of the object for oneself takes on new meaning. Rather than aiming for exclusivity, the possession is for the benefit of one's developing self.

The child needs objects to act; they are like nourishment for his spirit... It has been said that man's greatest delight is to possess things. No! Man's greatest delight is using them! Using them to perfect himself and at the same time to improve his environment. There is a constant interaction between the individual and his environment. The use of things shapes man, and man shapes things. This reciprocal shaping is a manifestation of man's love for his surroundings. ${ }^{[17]}$

But what of the mediator? Is this «constant interaction between the individual and his environment» free of mediation? Quite the contrary. In the case of the prepared Montessori environment, the mediation is a quality of the environment itself. As we saw with Miss $G$., the role of the teacher is to freely offer access to materials and experiences that will meet the needs of the Absorbent Minds of her students. 
And so we discovered that education is not something which the teacher does, but that it is a natural process which develops spontaneously in the human being. It is not acquired by listening to words, but in virtue of experiences in which the child acts on his environment. The teacher's task is not to talk, but to prepare and arrange a series of motives for cultural activity in a special environment made for the child. ${ }^{[18]}$

The subordinate, nearly invisible role of the Montessori teacher in her classroom was, and continues to be, a reversal of standard models of education. Montessori trained her teachers to relinquish center stage and give the children credit for their own learning. This not only facilitates education, but it also mitigates against rivalry. Much like the retailer's credo that the customer is always right, Montessori teachers know that the child is rarely at fault in instances of misbehavior or failure to learn. To correct problems, teachers seek first to adjust the environment, altering things such as the class routine, the materials on the shelf or the way in which the teacher has approached and engaged with the child. This attitude of humility coupled with respect for the self-educating powers of the Absorbent Mind, helps protect the Montessori classroom from the damaging effects of rivalry.

What happens when adults fail to meet the needs of children for an environment free from rivalry in which they can act according to the dictates of the Absorbent Mind? It is then that the acquisitive desire of the Absorbent Mind becomes possessive desire. Montessori summarizes her understanding of this transition in a delightful short essay with an amusingly long title: The Form Education must take to be able to help the World in our Present Circumstances. She remarks,

But if this does not happen -if something prevents the child from actinghe begins to want to possess the things all around him. Rather than working together with others, the child quarrels with them. The result of his association with others is not collaboration but conflict. ${ }^{[19]}$

Prophetically she adds, «Two paths lie open in the development of personality -one that leads to the man who loves and one that leads to the man who possesses... Man does not take one or the other of these paths through his own free choice; the one he takes depends on whether he has developed normally or abnormally».[20]

\section{Conclusion}

From her observations of the Absorbent Mind at work in childhood, Montessori concluded that love is natural, hate is not; cooperation is normal, rivalry is not. Lest this sound too much like a refutation of the "selfish gene" in favor of postulating genetic compassion, we must note that like Girard, Montessori's analysis of human behavior was grounded in the mimetic mechanism. Love of the environment, as she observed it in children guided by the Absorbent Mind, preserves the reality of the object towards which it is directed. It can be said, and Montessori certainly did, that the child «loves» the small pitcher designed for her hand so that she can perfect the grasping of the handle and the delicate operation of tipping the pitcher so that the water flows without 
spilling into the child-sized glass. Though she grasps the pitcher, she does not desire to possess it for her own. For normalized children, a pitcher is always and only a pitcher.

This is in stark contrast to acquisitive desire infected by rivalry, in which the object is no longer an object that can be appreciated for itself. It has become distorted, imbued with the being of another, and so it can no longer support the development of a new individual. All it can do is convey inadequately and unsatisfactorily the flawed being of another. Dr. Montessori recognizes that the desire to possess for oneself leads to conflict, but also claims that this is not «normal» human behavior. Rather it is evidence of «abnormal» development brought about by preventing the child from acting upon the pull of mimetic desire to make use of the environment.

The question of mediation becomes central at this point, for adults are the child's mediators and the culture that surrounds the child is an adult creation. Forcing children to fit into a world built to suit adult needs and desires is nothing other than adults abandoning their role as benevolent mediator for one of rival. Montessori offers this example of a well-meaning mother inadvertently thwarting the working of the Absorbent Mind:

Often what we call naughtiness on the part of the individual child is rebellion against our own mistakes in educating him. The coercive means that we adopt toward children are what destroy their natural tranquility. $A$ healthy child, in his moments of freedom, succeeds in escaping from the toys inflicted upon him by his parents and in securing some object that arouses the investigating instinct of his mind: a worm, an insect, some pebbles, and so forth; he is silent, tranquil, and attentive. If the child is not well, or if his mother obliges him to remain seated in a chair, playing with a doll, he becomes restless, cries, or gives way to convulsive outbursts («bad temper»). The mother believes that educating her child means forcing him to do what is pleasing to her, however far she may be from knowing what the child's real needs are, and unfortunately we must make the same statement regarding the schoolteachers! Then, in order to make him yield to coercion, the mother punishes the child when he rebels and rewards him when he is obedient. By this method we drive a child by force along paths that are not natural to him. ${ }^{[21]}$

In the normal functioning of the Absorbent Mind, metaphysical and acquisitive desire are united into one force aimed at the creation of an adult human being out of the child. Montessori believed that the key to a more peaceful future for humanity lay in minimizing the interference with the normal functioning of desire in childhood and she cautioned against the adult tendency to correct behaviors in children which do not conform with adult expectations. By imposing our will on children, we facilitate the move from acquisitive to possessive desire to the detriment of the child's development, potentially facilitating the emergence of an adult more susceptible to rivalry and conflict.

Because Dr. Montessori's hope in a more peaceful future is one rooted in a keen awareness of the origin of conflict in mimetic desire, it marries well with Girard's prophetic apocalypticism. As Girard says in Battling to the End, "Saying that chaos is near is not incompatible with hope, quite to the contrary. However, hope has to be seen in relation to an alternative that leaves only the choice between total destruction and realization of the Kingdom». [22] Living and working 
before, during and after the World Wars of the twentieth century, Montessori needed very little imagination to entertain the option of «total destruction». What her work provides is the assist our imaginations seem to need in order to visualize a path to the «realization of the Kingdom». That path, to the disappointment of our pride, will be paved by children.

\section{Notes}

[1] This text appears as a The Raven Foundation poster, entitled "Mimetic Desire», and can be found at https://www.ravenfoundation.org/wp-content/uploads/2020/07/MimeticDesire-Infographicp2_ Page_2-796x1030.png

[2] Jean-Michel Oughourlian, The Genesis of Desire, trans. Eugene Webb (East Lansing, MI: Michigan State University Press, 2010), 17.

[3] Oughourlian, The Genesis of Desire, 19.

[4] René Girard with Peirpoalo Antonello and João Cezar de Castro Rocha, Evolution and Conversion: Dialogues on the Origins of Culture, (London, UK: Continuum International Publishing, 2007), 64.

[5] Maria Montessori, The Secret of Childhood, trans. M. Joseph Costello, S.J. (New York, NY: Ballantine Books, 1966), 143-144.

[6] Roel Kaptein with the cooperation of Duncan Morrow, On the Way of Freedom, (Dublin, Ireland:The Columba Press, 1993), 9.

[7] Maria Montessori, The Absorbent Mind, trans. Claude A. Claremont (New York, NY: Dell Publishing, 1967), $19,36$.

[8] Maria Montessori, Education and Peace, trans. Helen R. Lane (Amsterdam, NL: Montessori-Pierson Publishing Company, 2007), 52.

[9] For more on the nonrivalrous presence required by adults in service of the Absorbent Mind, see my article for Contagion, Vol. 19, posted on academia.edu, The Montessori Method: The Development of a Healthy Pattern of Desire in Early Childhood.

[10] Montessori, The Absorbent Mind, 170.

[11] Montessori, The Secret of Childhood, 144-145.

[12] Antonio Damasio, Descartes' Error: Emotion, Reason and the Human Brain, (New York, NY: Penguin Books, 1994), xxi.

[13] Montessori, The Absorbent Mind, 180-181.

[14] Montessori, The Absorbent Mind, 156.

[15] Oughourlian, The Genesis of Desire, 39.

[16] Montessori, Education and Peace, 57.

[17] Montessori, Education and Peace, 57.

[18] Montessori, The Absorbent Mind, 19

[19] Montessori, Education and Peace, 57.

[20] Montessori, Education and Peace, 57-58.

[21] Maria Montessori, Pedagogical Anthropology, trans. Frederic Taber Cooper (New York, NY: Frederick A. Stokes Company, 1913), 442-443.

[22] René Girard, Battling to the End: Conversations with Benoît Chantre, trans. Mary Baker (East Lansing, MI: Michigan State University Press, 2010), 119. 